\title{
AS NOVAS POLÍTICAS MIGRATÓRIAS BRASILEIRAS E O IMPACTO NA VIDA DOS IMIGRANTES VENEZUELANOS
}

\author{
Luís Felipe Perucci de Lacerda ${ }^{\mathrm{i}}$ \\ Lirian Melchiorii
}

\begin{abstract}
Resumo: o presente artigo traz uma discussão sobre a crise políticoeconômica-social, gerada no Governo de Nicolás Maduro, que afeta grande parte da população venezuelana e que culminou em uma forte migração para países vizinhos, incluindo o Brasil. Buscou-se ainda analisar a recepção destes migrantes em território brasileiro verificando a reformulação das políticas migratórias e contextos xenofóbicos. Como recurso, foi realizado um levantamento bibliográfico sobre políticas migratórias e a mobilidade dos venezuelanos para o Brasil, além da análise de fontes secundárias e primárias para entender os contextos espaciais e econômicos que esta migração adquire. Desta forma, procura-se evidenciar as dificuldades enfrentadas pelo migrante e a possibilidade de redefinição de novas territorialidades na busca por refúgio em outro país.

Palavras-chave: migração; Venezuela; territorialidade.
\end{abstract}

\section{THE NEW BRAZILIAN MIGRATION POLICIES AND THE IMPACT ON THE LIVES OF VENEZUELAN IMMIGRANTS}

\begin{abstract}
: this article discusses the political-economic-social crisis, generated by the Nicolás Maduro government, which affects a large part of the Venezuelan population and which culminated in a strong migration to neighboring countries, including Brazil. We also sought to analyze the reception of these migrants in Brazilian territory, verifying the reformulation of migration policies and xenophobic contexts. As a resource, a bibliographic survey was conducted on migratory policies and the mobility of Venezuelans to Brazil, in addition to the analysis of secondary and primary sources to understand the spatial and economic contexts that this migration acquires. In this way, it seeks to highlight the difficulties faced by migrants and the possibility of redefining new territorialities in the search for refuge in another country.

Keywords: migration; Venezuela; territoriality.
\end{abstract}

\section{LAS NUEVAS POLÍTICAS MIGRATORIAS BRASILEÑAS Y EL IMPACTO EN LA VIDA DE LOS INMIGRANTES VENEZOLANOS}

\footnotetext{
' Bacharel em Geografia, Universidade Federal Rural do Rio de Janeiro, luisfelipeplacerda@gmail.com; https://orcid.org/0000-0003-3006-4104.

ii Professora Doutora do Curso de Geografia da Universidade Federal Rural do Rio de Janeiro. lirianmelchior@hotmail.com; https://orcid.org/0000-0002-8571-2538.
} 
Resumen: este artículo presenta una discusión sobre la crisis políticoeconómica-social generada en el Gobierno de Nicolás Maduro, que afecta a una gran parte de la población venezolana y culminó con una fuerte migración a países vecinos, incluido Brasil. También buscamos analizar la acogida de estos migrantes en territorio brasileño verificando la reformulación de las políticas migratorias y los contextos xenófobos Como recurso, se realizó una encuesta bibliográfica sobre las políticas migratorias y la movilidad de los venezolanos a Brasil, además del análisis de fuentes secundarias y primarias para comprender los contextos espaciales y económicos que adquiere esta migración. Así, busca poner de relieve las dificultades a las que se enfrenta el migrante y la posibilidad de redefinir nuevas territorialidades en la búsqueda de refugio en otro país.

Palabras clave: migración; Venezuela; territorialidad.

\section{Introdução}

O fenômeno migratório internacional atual vem se caracterizando pelo desenvolvimento e constituição de sociedades em redes. $O$ estudo destes deslocamentos possibilitou a análise da porosidade das fronteiras nacionais, étnicoculturais e identitárias, uma vez que nos terrenos das trocas materiais e simbólicas se confrontam indivíduos e culturas muito diferentes. Dessa forma, as práticas de deslocamento devem ser percebidas como constitutivas de significados culturais em lugar de serem apenas uma extensão ou transferência desses significados. As redes sociais construídas na migração têm a capacidade de produzir modos de organização que ultrapassam as fronteiras de um Estado, de um território definido por uma linha geopolítica ou dois lados separados e vigiados arbitrariamente, mas também ligados por práticas legais e ilegais de cruzamentos, trocas e comunicações (CLIFFORD, 1999: 13).

Pensando desta maneira é que nos propusemos a estudar o recente deslocamento de venezuelanos(as) para Brasil - iniciado de forma mais intensa em 2017 - e suas diferentes perspectivas, buscando compreender as relações sócio-espaciais envolvidas na busca por trabalho, estadia, alimentação, segurança; refletindo assim, sobre a mobilidade humana. 
Imersa em uma grande crise humanitária, a Venezuela passou a ser um lugar de instabilidade e vulnerabilidade para quem vive no país, o que obrigou milhares de pessoas a deixarem o seu país em busca de mínimas condições de sobrevivência. De acordo com a previsão realizada pelo FMI (Fundo Monetário Internacional) no ano de 2016, a economia da Venezuela iria encolher $12 \%$ e poderia alcançar um índice superior a $2.000 \%$ em inflação, aumentando mais ainda a recessão econômica. O controle de preços e a política decretada por Nicolás Maduro de retenção de dólares gerou consequências estarrecedoras para a população como a escassez de produtos básicos, essenciais ao desenvolvimento e a vida digna da população como: leite, ovos, farinha, sabão e papel higiênico (VEJA, 2016). Em matéria publicada recentemente pelo site UOL, confirmaram-se as projeções da superinflação. Nos primeiros meses de 2019 a inflação acumulada chegou a 3.326\%, fato que elucida a grave crise enfrentada pela Venezuela. (UOL, 2019)

O movimento transfronteiriço realizado pelos migrantes entre a Venezuela e o Brasil, aparece como uma alternativa devido ao menor custo, não precisando gastar com viagens aéreas - muitos se deslocam de ônibus ou até mesmo a pé. A fuga de uma situação de crise de seu país levou milhares de venezuelanos a buscarem abrigo em terras brasileiras, no entanto, para aqui se fixarem, a necessidade de trabalho se faz latente, o que implica em uma outra dificuldade para os imigrantes pois o Brasil enfrenta um elevado nível de desemprego atualmente.

Com a crescente migração dos venezuelanos para o Brasil, os pedidos de refúgio cresceram muito. Em terras brasileiras, mesmo assegurados pelas leis que protegem àqueles que pedem algum tipo de ajuda humanitária, os venezuelanos têm sofrido preconceitos por parte da população e do poder político local o que acaba por dificultar o processo de adaptação no Brasil. Estas são questões que tem sido insistentemente discutida, pois em tempos de fluidez de mercadorias e de capital, aos indivíduos migrantes são impostas todo tipo de restrições, implicando até mesmo na proliferação de barreiras físicas como muros e cercas, além da militarização de fronteiras para impedir a entrada de migrantes (PÓVOA-NETO, 2018; HAESBAERT, 2017). 
Os discursos midiáticos em relação aos migrantes revelam algumas representações que tornam explícitos certos aspectos da migração e acabam invisibilizando outros. A mídia, através de suas publicações, constrói exposições acerca de determinados grupos, como no caso das notícias sobre os movimentos migratórios, a exemplo da Venezuela, com a crise migratória. Esse discurso, da forma como é construído, pode produzir representações que acabam desconsiderando quaisquer personagens que fujam da norma instituída pela imprensa.

Ao tratarem do tema da migração, bem como de qualquer outro, os meios de comunicação fazem uso do discurso não-acadêmico (mesmo que eventualmente informado por membros da academia), utilizando a informação transformada em notícia como meio para conquista e consolidação de posições ante o mercado dos leitores. Para isso, podem apelar ao recurso da reiteração de idéias já estabelecidas e, curvando-se ao imperativo da informação breve e imediata, não privilegiar o aprofundamento analítico sobre processos sociais com alto grau de complexidade (PÓVOA-NETO, 2006: 57).

Para entender as diferentes consequências do processo migratório foi realizada uma análise bibliográfica buscando referências teóricas sobre a migração e sobre as questões políticas, econômicas e sociais que estão envolvidas neste processo. Também foi realizada uma análise de fontes secundárias (IBGE, IPEA, CONECTAS, ACNUR, ONU) além de um acervo de noticiais veiculadas pela mídia sobre a migração de venezuelanos para - Brasil. Para compreender melhor a situação real vivenciada pelos migrantes, ainda foram aplicados questionários a alguns grupos de venezuelanos encontrados no Facebook. Esta ferramenta de análise se mostra bastante importante, pois possibilita o acesso aos migrantes de forma virtual e traz ao debate o impacto real sofrido por estas pessoas.

Assim, este texto está dividido em quatro partes: entendendo o deslocamento dos venezuelanos para o Brasil; a migração de venezuelanos para o Brasil e a reação dos brasileiros; a nova lei do migrante e os venezuelanos e a questão do refúgio e território - à guisa de conclusão, onde procura-se trazer uma reflexão sobre os contextos sóciopolítico-econômicos e espaciais que envolvem um processo migratório e também a 
vulnerabilidade e dificuldades que estes enfrentam durante o processo de adaptação e de reterritorialização no país de destino.

\section{Entendendo o deslocamento dos venezuelanos para o Brasil}

Buscando entender a crise na Venezuela e a consequente saída de parte de sua população para países vizinhos, achamos importante resgatar um pouco da história de seus mais recentes presidentes, Hugo Chaves (1999 a 2012) e Nicolás Maduro (2013 a atual).

A escalada de Chávez ao poder, em 1999, marcou o fim de uma era para a população venezuelana. Os partidos políticos que eram tidos como tradicionais se dissipam à nova realidade, certificados pela votação expressiva de um modelo alternativo. Até o ano de 2004, Chávez estava somente preocupado em aderir a um novo modelo de Constituição, argumentando que a anterior era incompatível com o momento histórico que se desenhava. Havia também a preocupação em realizar uma série de reformulações agrárias, sociais e, sobretudo, petroleiras

SANTOS e VASCONCELOS (2016: 3) dão destaque em seu texto dizendo que o governo chavista estava interessado em propostas em que vinham de confronto com a classe burguesa e os setores mais conservadores do país. Fazendo com que a reforma agrária fosse um assunto a ser debatido e realizado, extrair por completo a participação das multinacionais para a extração de petróleo do país, além de autorizar um regime de cogestão entre o Estado e os funcionários para que fossem reerguidas as empresas falidas.

Chávez conseguiu fazer grandes mudanças na estrutura social, fazendo com que a burguesia fosse desmoralizada - classe que tinha o poder até o momento. Ocorreu então a ascensão do povo oprimido, que passou também a ter voz ativa em tudo que era decidido no país. Hugo Chávez tinha uma postura totalmente nacionalista, com uma 
vontade de transformar não só a Venezuela, mas a América Latina, em nome do socialismo que apelidava de socialismo do século $X X$ - modelo seguido pelo atual presidente da Venezuela - Nicolás Maduro.

Porém, a política econômica de Chávez ficou basicamente centrada na exploração do petróleo não apresentando grandes investimentos em outras áreas produtivas. Com a morte de Hugo Chávez, Nicolás Maduro assume mantendo a mesma linha política. No entanto, uma forte crise petrolífera explode no mundo, diminuindo em grande escala o preço dos barris de petróleo, produto de extrema importância para a economia do país girar. As consequências socioeconômicas foram devastadoras e são sentidas até hoje. Se por um lado a forte alta do preço do petróleo posterior ao ano de 2005 possibilitou uma rápida ascensão da economia venezuelana sob a gestão de Hugo Chávez, por outro, a queda do preço após o ano de 2015, sob a gestão de Nicolás Maduro, teve efeitos devastadores para a Venezuela.

Tabela 1: Preço do barril de petróleo em dólares

\begin{tabular}{|c|c|}
\hline Ano & Preço do barril (em dólares) \\
\hline 2013 & 112.93 \\
\hline 2014 & 107.57 \\
\hline 2015 & 48.42 \\
\hline 2016 & 30.80 \\
\hline 2017 & 46.19 \\
2018 & 68.13 \\
2019 & 60.85 \\
\hline
\end{tabular}

Fonte: G1 (2019). Preço do petróleo Brent se estabiliza ao redor de US\$ 64 com foco na retomada de produção saudita.

https://g1.globo.com/economia/noticia/2019/09/23/preco-do-petroleo-brent-se-estabilizaao-redor-de-us-64-com-foco-na-retomada-de-producao-saudita.ghtml

A crise humanitária então foi instalada. Notou-se a falta de utensílios básicos em todas as prateleiras, a inflação disparou para números assustadoramente altos, a economia foi em queda livre e a moeda do país foi completamente desvalorizada. A Venezuela presenciou uma crise econômica, social e política. Por outro lado, a oposição, que antes 
estava representando uma minoria no congresso, ganhou força e voz, devido à falta de estabilidade econômica e política e seu discurso tornou-se favorável e bem-vindo pela população que ansiava por uma melhora imediata. SIMÕES discute isso em seu artigo:

O que o Human Right Watch chama de "Crise Humanitária" é a grave e generalizada violação de Direitos Humanos na Venezuela. Falta de medicamentos básicos que dificultam o acesso a serviços básicos de saúde e tratamento de doenças crônicas como pressão alta e diabetes. Falta de alimentos, o que gerou na população Venezuelana uma "desnutrição severa". A Unicef revelou em relatório publicado que $3,4 \%$ das crianças venezuelanas sofriam de desnutrição em 2013, o último ano refletido nas estatísticas que o Governo do presidente Nicolás Maduro ofereceu ao organismo internacional. Esse número cresceu segundo dados da FAO divulgados em 2017 (UNICEF apud SIMÕES, 2017: 49).

Percebe-se, assim, que a situação social na Venezuela era bastante preocupante, com altas taxas de desemprego, uma grave crise hospitalar, além da falta de acesso a produtos básicos de consumo. Esta situação tem sido fortemente agravada por conta dos embargos econômicos que países opositores ao Chavismo têm colocado à Venezuela. Um dos principais causadores dessa crise é os EUA, que impôs sanções à Venezuela resultando na retenção da exportação de petróleo para aquele país, além de bloqueios de medicamentos e alimentos.

Em meio a tantas dificuldades que começaram a ser impostas à população, esta começou a se deslocar pelos países vizinhos (Colômbia, Equador, Peru, Brasil), além de EUA e Espanha, em busca de trabalho e alimentos.

Tabela 2: Número de venezuelanos morando fora da Venezuela (2005-2018)

\begin{tabular}{|c|c|c|}
\hline Ano & América do Sul & No Mundo \\
\hline 2005 & $55 \mathrm{mil}$ & $437 \mathrm{mil}$ \\
\hline 2010 & $68 \mathrm{mil}$ & $557 \mathrm{mil}$ \\
\hline 2015 & $87 \mathrm{mil}$ & $696 \mathrm{mil}$ \\
\hline $2017 / 2018$ & $1.5 \mathrm{milhão}$ & 2.5 milhões \\
\hline
\end{tabular}

Fonte: Gazeta do Povo (2019) Cinco gráficos que explicam a crise na Venezuela. https://www.gazetadopovo.com.br/mundo/cinco-graficos-que-explicam-a-crise-da-venezuela20k14seeg7h03hs2pg7pi52ad/. 
O Estado Bolívar ao sul da Venezuela e o Estado de Roraima na Região Norte do Brasil possuem similitudes, tais como o fato de se constituírem em grandes espaços em relação aos seus respectivos territórios nacionais. Viverem processos de expansão da fronteira econômica, cujos programas oficiais de exploração de recursos naturais enfatizavam o caráter de "espaços vazios", culminando com políticas de ocupação baseadas no conceito de desenvolvimento vinculado à doutrina de Segurança Nacional. São palcos de constantes conflitos pelo controle dos recursos naturais travados por diversos atores sociais (índios, garimpeiros, madeireiros, empresários, fazendeiros, militares); possuem populações indígenas significativas e estão situados em áreas de fronteira internacional, portanto, em área que delimita a soberania das duas nações.

\section{Figura 1: Mapa da fronteira do Brasil com a Venezuela,} em especial com o estado de Roraima.

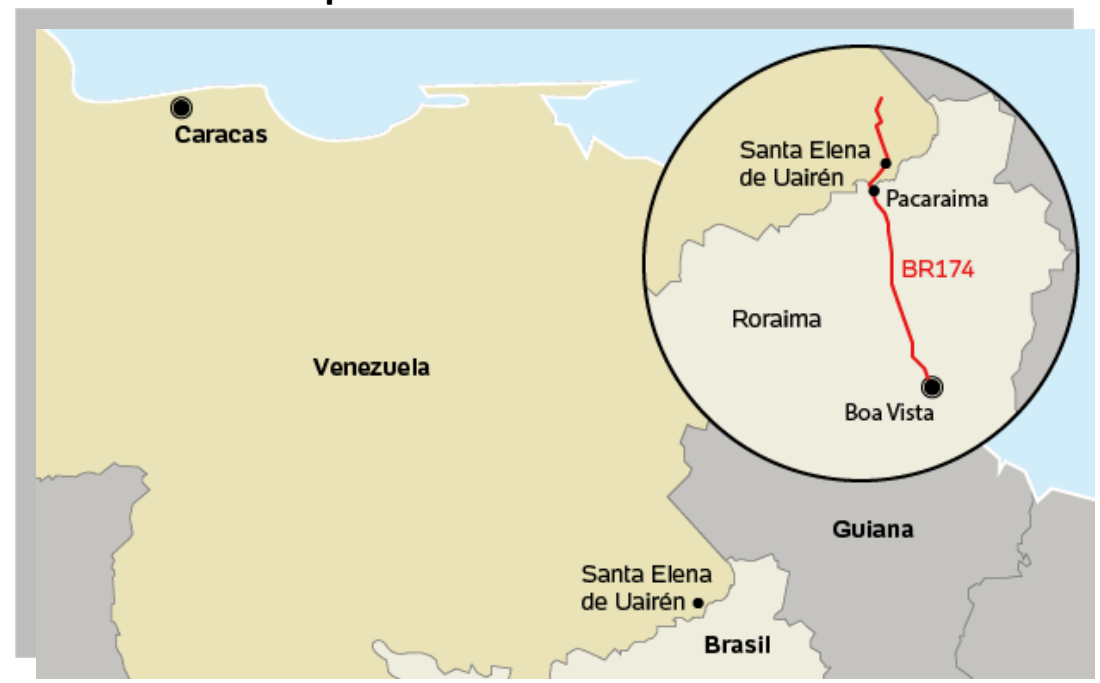

Fonte: Amazônia.org (2018) Transporte carro ou dias a pé: como é a travessia dos venezuelanos para viver no Brasil

https://amazonia.org.br/2018/02/transporte-caro-ou-dias-a-pe-como-e-a-travessia-dosvenezuelanos-para-viver-no-brasil/

A figura 1 evidencia a proximidade entre os municípios fronteiriços de Gran Sabana e Pacaraima que também apresentam características muito similares quanto à inserção regional e ocupação dos territórios estaduais e nacionais. São munícipios de projetos de expansão agrícola, áreas de intensa exploração mineral ao longo de suas histórias, e 
possuem um grande contingente de população indígena. Estas semelhanças facilitam as relações transfronteiriças implicando em travessias constantes entre os municípios vizinhos, onde os imigrantes procuram saciar suas necessidades básicas sem deixarem efetivamente seu território de origem.

\section{A migração de venezuelanos para o Brasil a reação dos brasileiros}

A migração venezuelana para o Brasil não produzia números considerados significativos, fato que teve uma mudança a partir de 2015, com pico de entradas no país em 2017, ultrapassando vinte mil ingressos. Esse maior movimento de entrada no país fez com que a mídia e o governo federal classificassem esse fluxo como crise humanitária. Segundo dados da Polícia Federal, entre 2017 e novembro de 2018, entraram no Brasil 199.365 venezuelanos através da fronteira da cidade de Pacaraima, em Roraima. Destes, 100.928 têm registro de saída do Brasil e 98.437 ainda estariam em território brasileiro. Tal fluxo migratório aumentou sobremaneira o número de solicitações de refúgio, que passou de 10.357 pedidos em 2016 para 73.410 em 2018 (POLÍCIA FEDERAL, 2018).

Recentemente vimos essa vinda de venezuelanos para o Brasil estampar todas as capas de jornais. Devido à alta demanda e falta de lugar para abrigar, Pacaraima viu-se em estado de calamidade pública. Os habitantes da capital acabaram vendo o seu lugar apropriado por pessoas de outro país e decidiram reivindicar seus direitos de uma forma brutal. Muitas foram às manifestações por parte da população e do poder político local registrando o descontentamento com a chegada de um número tão grande pessoas nas cidades de Roraima.

Essas reflexões atestam a profunda complexidade da relação entre criminalidade, migração e direito. Embora sofram numerosas violações de direitos humanos, tanto nos países de origem como naqueles de trânsito e de chegada, muitos migrantes e solicitantes de refúgio, com frequência, acabam sendo perseguidos por dispositivos legislativos que visam, antes 
que o respeito da dignidade do ser humano, o controle do excedente social (MARINUCCI, 2015: 8).

Essa xenofobia por parte dos brasileiros contra os venezuelanos passou a ser bastante discutida nas redes sociais, tendo defensores e opositores. Muitas pessoas tentando justificar a represália contra os migrantes, por erros cometidos por um grupo ínfimo. Em Roraima, por exemplo, a população local expulsou os venezuelanos ao som do hino nacional, a partir deste momento a vinda de venezuelanos para a cidade se tornou algo insustentável.

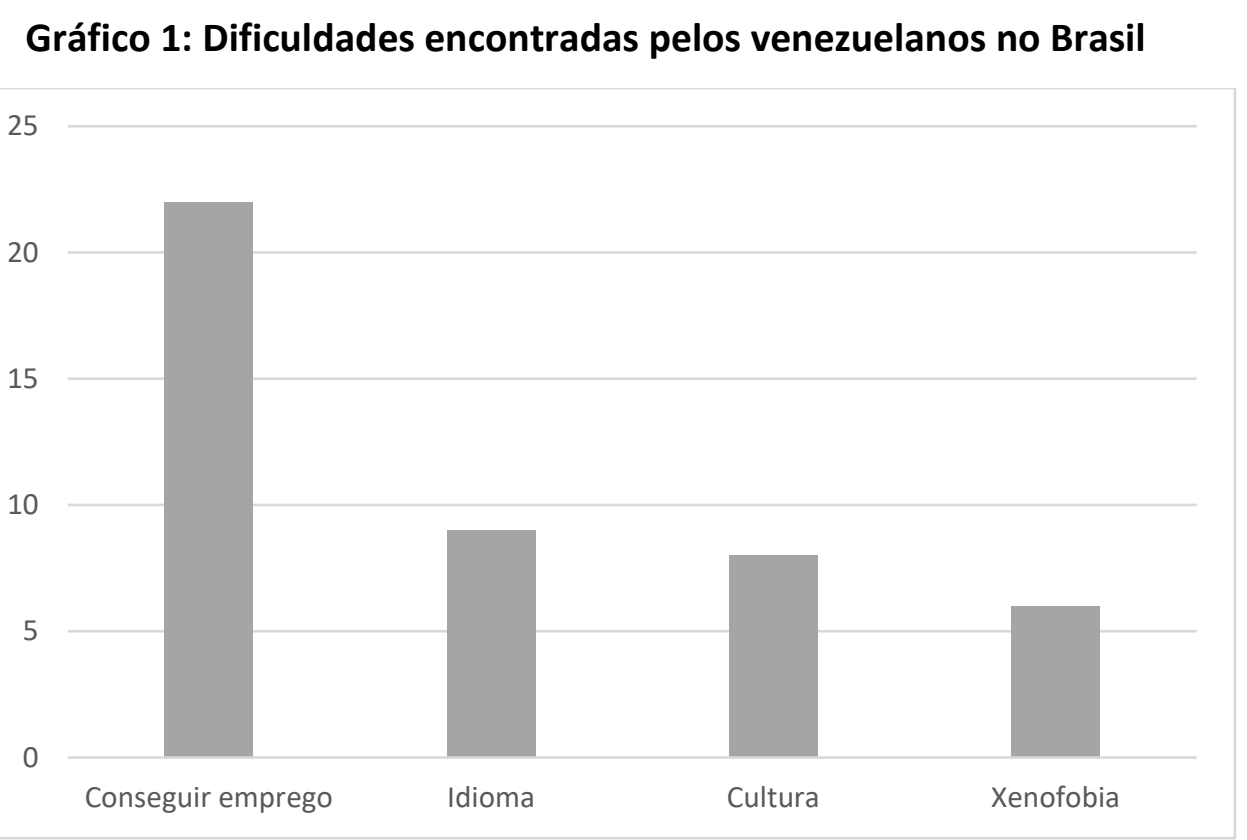

Fonte: Dados coletados através da pesquisa primária realizada com grupos de migrantes venezuelanos encontrados no Facebook, 2019.

Em uma pesquisa feita pela ACNUR, publicada pelo jornal DESTAK (2019), a discriminação sofrida pelos venezuelanos alcançou um nível de $41 \%$. O que mostra que há uma dificuldade em estabelecer uma máxima quando se trata deste assunto. No questionário aplicado, a xenofobia não se apresenta enquanto elemento de destaque, mas as demais respostas sugerem um indicativo de preconceito (dificuldade na 
comunicação e para arrumar emprego), além dos temas veiculados na mídia, deixando claro que a recepção dos venezuelanos pelos brasileiros foi um pouco tempestuosa, estampando a capa de muitos jornais pelo Brasil.

Os episódios de xenofobia contra os venezuelanos relatados demonstram que casos de discriminação e agressões contra migrantes são muito frequentes, principalmente na cidade de Pacaraima, devido esta ser uma cidade muito pequena e não ter recursos suficientes para os próprios moradores, tampouco para pessoas de fora do país. Fica explícito então o ressentimento por parte dos brasileiros tanto pela precarização ainda maior de serviços públicos, pressionados pela demanda dos novos usuários, como pela sensação de insegurança.

O processo de criminalização do migrante cria condições socialmente aceitas para culpabilizar o indivíduo, que já se encontra em uma situação vulnerável, por todas as situações precárias que dada sociedade está vivendo - aumento da violência, desgastes dos serviços públicos, falta de empregos - levando o migrante a assumir a culpa por um Estado que não consegue se responsabilizar por seus problemas sociais e atribui ao Outro a precariedade ou inexistência dos seus serviços. Assim, ocorre o aumento de manifestações xenofóbicas e preconceituosas contra os migrantes (PÓVOA-NETO, 2005, 2018).

Vale ressaltar que a mobilidade populacional implica em busca por melhores condições de vida em outros territórios, portanto o acesso ao trabalho se faz necessário para que o migrante possa ter condições de manter sua vida no país de destino. No entanto, a Organização Internacional para as Migrações (OIM) aponta que apenas 9\% dos venezuelanos que entram no Brasil por Roraima conseguem um emprego formal nas primeiras semanas após chegarem, antes de seguirem para outros destinos. Em levantamento feito com mais de 4,1 mil pessoas em 13 municípios do estado, a agência da ONU revela que $59 \%$ desses refugiados e migrantes estão sem trabalho. Um em cada três tem dificuldade em ter o que comer. De acordo com o organismo das Nações Unidas, 32\% dos venezuelanos entrevistados tinham emprego em seu país de origem. A publicação da agência da ONU ressalta que $29 \%$ dos venezuelanos possuíam alguma 
formação especializada (ensino médio técnico, tecnólogo ou faculdade) completa ou incompleta, com quase $15 \%$ tendo frequentado uma universidade, ainda que não tivessem acabado o curso. Segundo o relatório, $61 \%$ dos entrevistados tinham concluído ou pelo menos iniciado o ensino médio (NAÇÕES UNIDAS, 2019).

Tabela 3: Principais países de destino dos imigrantes venezuelanos em 2018

\begin{tabular}{|c|c|}
\hline País de destino & Número \\
\hline Colômbia & 1.1 milhão \\
\hline Peru & $506 \mathrm{mil}$ \\
\hline Chile & $288 \mathrm{mil}$ \\
\hline Equador & $221 \mathrm{mil}$ \\
\hline Argentina & $130 \mathrm{mil}$ \\
\hline Brasil & $96 \mathrm{mil}$ \\
\hline
\end{tabular}

Fonte: BBC (2018) Brasil recebe apenas 2\% dos 2,3 milhões de venezuelanos expulsos pela crise. https://www.bbc.com/portuguese/brasil-45251779.

Os venezuelanos, ainda que vivenciem uma situação de conflitos político-econômicos e sociais em seu país - o que poderia diferir de uma migração por trabalho que impulsiona as engrenagens do mercado capitalista -, ao chegar ao Brasil, em busca de visto humanitário, também terão de buscar uma inserção no mundo do trabalho para garantirem o sustento de suas famílias, porém as dificuldades encontradas pelos venezuelanos para obterem emprego em Pacaraima e na capital Boa Vista é indiscutível e explícito no questionário aplicado. Muitos acabam desabrigados, desempregados e ocorre o agravamento de suas condições precárias de vida acirrando as preexistentes fragilidades sociais da região, especialmente na capital Boa Vista. As históricas dificuldades econômicas enfrentadas pelo Estado e a profunda crise econômica pela qual passa o Brasil já seriam suficientes para causar processos de efervescência social no território em questão, porém estes estão sendo agravados num contexto de progressivo crescimento demográfico com a chegada dos migrantes venezuelanos. Assim, ocorrem adesões à informalidade laboral, à execução de atividades que são consideradas proibidas e as ocorrências de conflitos entre estrangeiros e parcelas minoritárias da população brasileira, refratárias aos efeitos colaterais da crescente presença destes em suas regiões. 


\section{Gráfico 2: Pedido de refúgio}

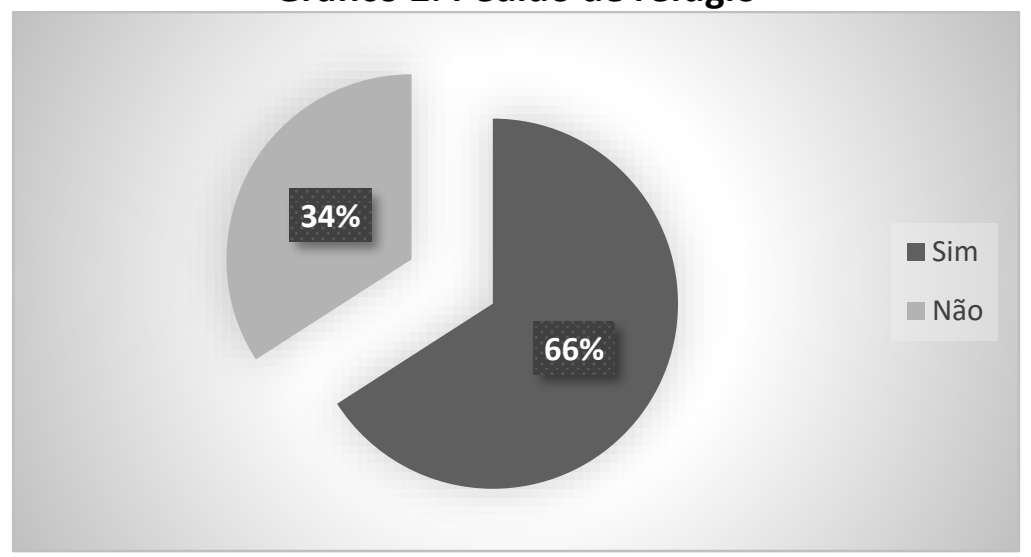

Fonte: Dados coletados através da pesquisa primária realizada com grupos de migrantes venezuelanos encontrados no Facebook, 2019.

Para aliviar as tensões ocorridas no Estado de Roraima, o Conselho Nacional de Direitos Humanos (CNDH), tomou a inciativa estratégica de interiorizar os venezuelanos para outros Estados do país. Segundo a ACNUR, mais de 4.700 venezuelanos já foram transferidos para outros 17 estados brasileiros. Os migrantes interessados neste processo fazem um cadastro, são imunizados, recebem informações sobre os municípios para os quais estão se deslocando, sobre acesso a serviços e sistemas de saúde e sobre como serão abrigados. Desta forma, eles podem ser acolhidos por outras instituições e não ficam em uma situação de vulnerabilidade maior, integrando-se de uma forma mais digna à sociedade brasileira (CONECTAS, 2018; ACNUR, 2019).

\section{A nova lei do migrante e os venezuelanos}

Os movimentos migratórios aumentaram muitos nos últimos anos e, com isso, o tratamento para com o migrante também precisou sofrer algumas alterações. Nas últimas décadas do século XX e nas primeiras décadas do século XXI, podemos observar 
grandes transformações no que diz respeito às políticas migratórias no Brasil e também em escala internacional.

Até pouco tempo no Brasil, a migração era ordenada por leis que foram instituídas no período militar, onde o imigrante era visto como uma ameaça aos indivíduos que pertenciam legitimamente àquele país, predominando o prisma da segurança nacional, que deveria manter de fora das nossas fronteiras àqueles que poderiam causar algum tipo de desordem. Não se pode olvidar que à época que o Estatuto foi concebido, a prioridade consagrada na legislação priorizava a segurança nacional, os interesses socioeconômicos do Brasil e o trabalhador nacional. O termo estrangeiro adotado pela norma citada indicava a existência de um indivíduo que "é natural de outro país; que não faz parte de uma família, de um grupo" (GUERRA, 2017: 96).

Após a década de 2000, novos grupos foram se somando a estes em terras brasileiras (vindos da Angola, Nigéria, Senegal, República Democrática do Congo e mais recentemente do Haiti), muitos destes migrantes vindos de países com sérios problemas, políticos ou ambientais sendo estes reconhecidos como refugiados. Com este novo cenário o Brasil precisou repensar suas leis tanto no que se refere à acolhida dos migrantes quanto aos direitos dos trabalhadores brasileiros em terras estrangeiras. Segundo OLIVEIRA (2017) a questão migratória do e para o Brasil precisou ser tratada de duas formas: primeiramente buscou-se regularizar os estrangeiros que viviam há um determinado tempo no país, no entanto, esta atitude não resolveu problemas essenciais obtendo uma política de migração clara com eixos de cooperação internacional. E ainda, os assuntos relativos a livre circulação de trabalhadores do MERCOSUL, acabou produzindo documentos normativos que não enfrentavam as questões migratórias com a profundidade necessária. Assim, a aparente "não política migratória" seria a manutenção, em grande escala, das práticas que foram herdadas do regime de exceção (OLIVEIRA, 2017: 172). No que diz respeito a direitos humanos, ROSSANA REIS (2004: 151) destaca que: 
No âmbito geral dos direitos humanos, apesar de suas limitações, as convenções relativas aos refugiados e apátridas representam um ponto de inflexão no direito internacional, pois pela primeira vez é reconhecida a existência do indivíduo no cenário internacional. Lentamente, direitos individuais universais independentes do Estado vão sendo reconhecidos, numa tendência que vinha se acentuando desde o fim da Segunda Guerra Mundial.

“O processo de criminalização
do migrante cria condições
socialmente aceitas para
culpabilizar o indivíduo, que já
se encontra em uma situação
vulnerável, por todas as
situações precárias que dada
sociedade está vivendo -
aumento da violência,
desgastes dos serviços públicos,
falta de empregos - levando o
migrante a assumir a culpa por
um Estado que não consegue se
responsabilizar por seus
problemas sociais e atribui ao
Outro a precariedade ou
inexistência dos seus serviços”.

É importante ressaltar que a partir desses debates em torno das leis migratórias, o Brasil era impulsionado e pressionado na direção dos avanços necessários, o que levaria a conflitos de posições e ideologias.

Há alguns anos atrás, o Estatuto do Estrangeiro tinha uma perspectiva que visava à segurança nacional e mostrava uma imagem do migrante como potencial ameaça aos interesses do país. A nova lei tem muitas mudanças, estabelecendo novos princípios que visa o combate à discriminação, homofobia e tem como ponto principal a igualdade de direitos. Além disso, trata da proteção de pessoas que vivem no exterior,

através de uma cooperação jurídica entre países. Também determina que haja um visto temporário para que o migrante que não se enquadre na lei do refúgio possa receber alguma ajuda. GUERRA (2017: 98) apresenta as principais conquistas no que se refere ao novo Estatuto do Migrante, afirmando que está o trata como sujeito e lhe garante uma série de direitos que devem ser respeitos em todo território nacional, são eles:

(...) a inviolabilidade do direito à vida, à liberdade, à igualdade, à segurança e à propriedade; direitos e liberdades civis, sociais, culturais e econômicos; direito à liberdade de circulação em território nacional; 
direito à reunião familiar do imigrante com seu cônjuge ou companheiro e seus filhos, familiares e dependentes; medidas de proteção a vítimas e testemunhas de crimes e de violações de direitos; direito de transferir recursos decorrentes de sua renda e economias pessoais a outro país, observada a legislação aplicável; direito de reunião para fins pacíficos; direito de associação, inclusive sindical, para fins lícitos; acesso a serviços públicos de saúde e de assistência social e à previdência social, nos termos da lei, sem discriminação em razão da nacionalidade e da condição migratória; amplo acesso à Justiça e à assistência jurídica integral gratuita aos que comprova- rem insuficiência de recursos; direito à educação pública, vedada a discriminação em razão da nacionalidade e da condição migratória; garantia de cumprimento de obrigações legais e contratuais trabalhistas e de aplicação das normas de proteção ao trabalhador, sem discriminação em razão da nacionalidade e da condição migratória; isenção das taxas de que trata esta Lei, mediante declaração de hipossuficiência econômica, na forma de regulamento; direito de acesso à informação e garantia de confidencialidade quanto aos dados pessoais do imigrante, direito à abertura de conta bancária; direito de sair, de permanecer e de reingressar em território nacional, mesmo enquanto pendente pedido de residência, de prorrogação de estada ou de transformação de visto em residência, e direito do imigrante de ser informado sobre as garantias que lhe são asseguradas para fins de regularização migratória (GUERRA, 2017: 98).

No Brasil já era comum instituições e leis que abordavam a questão migratória. A Lei $n^{\circ}$ 13.445/2017 (BRASIL, 2017), que institui a Lei de Migração, é vista como uma das mais modernas no mundo no que se refere à garantia de Direitos Humanos dos migrantes. ${ }^{1}$ Substituiu a Lei $n^{\circ}$ 6.815, de 19 de agosto de 1980 (BRASIL, 1980), mais conhecida como Estatuto do Estrangeiro, que tinha como base uma forte concepção de segurança nacional e enxergava o imigrante como uma ameaça a esta. ${ }^{2}$ A Lei de Migração corrente já não entende mais o imigrante como uma ameaça, mas como indivíduo de direitos iguais como qualquer cidadão nacional, em conciliação com os princípios inscritos na Constituição Federal de 1988.

\footnotetext{
${ }^{1}$ Esta Lei dispõe sobre os direitos e o dever do migrante e do visitante e regula a sua entrada e estada no País e estabelece princípios e diretrizes para as políticas públicas para o emigrante.

2 Em tempo de paz, qualquer estrangeiro poderá, satisfeitas as condições desta Lei, entrar e permanecer no Brasil e dele sair, resguardados os interesses nacionais. Na aplicação desta Lei atender-se-á precipuamente à segurança nacional, à organização institucional, aos interesses políticos, socioeconômicos e culturais do Brasil, bem assim à defesa do trabalhador nacional.
} 
A Lei de Migração concedeu aos imigrantes uma série de benefícios que até o momento eram conferidas apenas aos nacionais e também regulou a admissão de diversos Direitos Universais previstos na Constituição. Esta lei prevê, entre outros, um processo simplificado de regularização migratória; acesso a serviços públicos de assistência social, saúde e previdência; não criminalização ou discriminação por razões migratórias; acesso à justiça e à assistência jurídica integral gratuita, quando comprovada hipossuficiência; direito à educação; e liberdade de ir e vir (GUERRA, 2017).

A migração de venezuelanos ocorre ao mesmo tempo à divulgação e à regulamentação da referida Lei de Migração. Portanto, em certa relevância, esta experiência empírica influenciou e ajudou na construção de um aparato legislativo sólido e eficaz para o acolhimento de imigrantes de forma segura, ordenada e regular. O fluxo migratório de venezuelanos para o Brasil tem uma natureza precária, emergencial e localizado em um estado sem estrutura para receber um grande fluxo migratório. As políticas públicas existentes são demasiadamente falhas para lidar com todas essas questões ao mesmo tempo e, então, algumas estratégias criadas pelo Governo Federal foram traçadas tomando por base essas premissas iniciais.

Tabela 4: Motivos apresentados pelos migrantes venezuelanos entrevistados para migrar para o Brasil

\begin{tabular}{|c|c|}
\hline Motivo & Porcentagem \\
\hline Questão econômica & $45 \%$ \\
\hline Questão Social & $6 \%$ \\
\hline Questão Política & $6 \%$ \\
\hline Todas as alternativas & $16 \%$ \\
\hline
\end{tabular}

Fonte: Dados coletados através da pesquisa primária realizada com grupos de migrantes venezuelanos encontrados no Facebook, 2019.

Outro avanço percebido na nova lei do migrante é a concessão de visto humanitário para os migrantes que estão passando por situações emergenciais de deslocamentos sejam estas motivadas por desastres ambientais ou conflitos sócio-político-econômicos. 
Este visto agiliza o processo de entrada e de garantia de direitos (incluindo de trabalhar) em terras brasileiras, no entanto, embora esta seja uma ação de acolhida positiva ainda não cria uma politica migratória com bases sólidas para receber as populações em situações de vulnerabilidade.

O visto temporário para acolhida humanitária poderá ser concedido ao apátrida ou ao nacional de qualquer país em situação de grave ou iminente instabilidade institucional, de conflito armado, de calamidade de grande proporção, de desastre ambiental ou de grave violação de direitos humanos ou de direito internacional humanitário, ou em outras hipóteses, na forma de regulamento (BRASIL, 2017, cp. 2. Art.14, § 3‥).

A aprovação de uma nova Lei do Migrante que assegure direitos e uma condição de vida digna no país, com certeza é um avanço, considerando que a política conservadora brasileira tem se mostrado muito forte, desta forma, é essencial que mecanismos sejam criados para que esta seja implementada em todos seus aspectos e realmente os direitos dos migrantes sejam preservados.

A nova lei vem tratando de direitos e deveres do migrante e do visitante no Brasil. Ela regula a entrada e a permanência de estrangeiros, estabelece normas de proteção ao brasileiro no exterior. E visa estabelecer alterações na nomenclatura do não nacional, substituindo a figura do estrangeiro para a do migrante, como se depreende da leitura do artigo 1 ㅇ:

Artigo 1 을 Esta Lei dispõe sobre os direitos e os deveres do migrante e do visitante, regula a sua entrada e estada no País e estabelece princípios e diretrizes para as políticas públicas para o emigrante. $\S 1$ Para os fins desta Lei, considera-se:

I. (VETADO);

II. imigrante: pessoa nacional de outro país ou apátrida que trabalha ou reside e se estabelece temporária ou definitivamente no Brasil;

III. emigrante: brasileiro que se estabelece temporária ou definitivamente no exterior;

IV. residente fronteiriço: pessoa nacional de país limítrofe ou apátrida que conserva a sua residência habitual em município fronteiriço de país vizinho; 
V. visitante: pessoa nacional de outro país ou apátrida que vem ao Brasil para estadas de curta duração, sem pretensão de se estabelecer temporária ou definitivamente no território nacional;

VI. apátrida: pessoa que não seja considerada como nacional por nenhum Estado, segundo a sua legislação, nos termos da Convenção sobre o Estatuto dos Apátridas, de 1954, promulgada pelo Decreto no 4.246, de 22 de maio de 2002, ou assim reconhecida pelo Estado brasileiro.

A nova lei garante ainda ao migrante o direito à associação, inclusive sindical, para fins lícitos; acesso a serviços públicos de saúde e de assistência social e à previdência social, nos termos da lei; amplo acesso à justiça e à assistência jurídica integral gratuita aos que comprovarem insuficiência de recursos; garante ainda o direito à educação pública; a garantia do cumprimento de obrigações legais e contratuais trabalhistas e da aplicação das normas de proteção ao trabalhador. Todos estes direitos devem ser respeitados sem discriminação em razão da nacionalidade e da condição migratória e ao migrante ainda guarda-se o direito de sair, de permanecer e de reingressar em território nacional, mesmo enquanto pendente pedido de residência, de prorrogação de estada ou de transformação de visto em residência; e direito do imigrante de ser informado sobre as garantias que lhe são asseguradas para fins de regularização migratória.

Direitos humanos são aqueles inerentes a toda pessoa humana simplesmente pela condição de ser pessoa, de existir. Tais direitos diferenciam-se dos chamados direitos fundamentais à medida que aqueles são princípios jurídicos, vetores axiológicos que guardam relação com documentos na esfera internacional, os quais reconhecem o ser humano como tal, independentemente de sua vinculação com determinada ordem constitucional (BATISTA e BONINI, 2017: 9).

Esta lei, portanto, se apresenta como um avanço no que se refere às políticas migratórias realizadas nos Estados capitalistas atualmente, o que possibilitou que os migrantes venezuelanos que para o Brasil vieram se sentissem confortáveis quanto à nova legislação. O gráfico abaixo apresenta a reação do migrante quanto a nova lei. 
Gráfico 3: Medo das políticas migratórias.

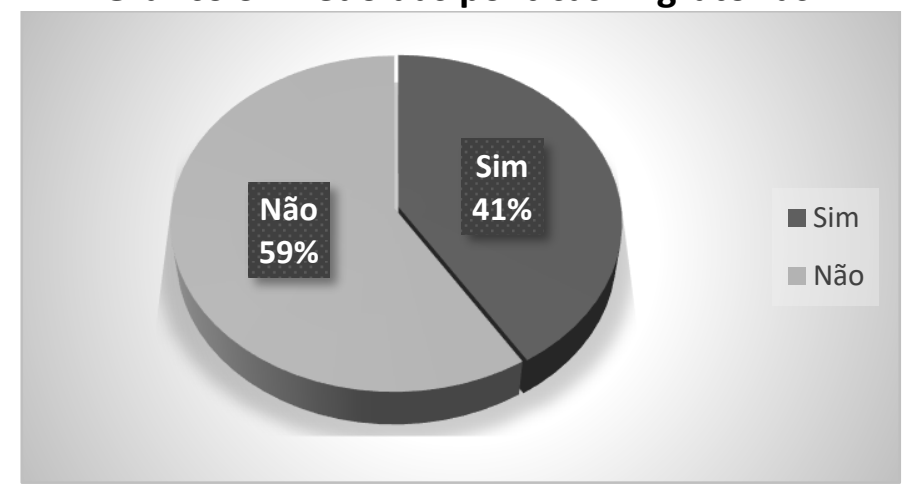

Fonte: Dados coletados através da pesquisa primária realizada com grupos de migrantes venezuelanos encontrados no Facebook, 2019.

No entanto, apesar dos avanços obtidos com a nova lei do migrante, há ainda uma grande diferença entre a lei e a prática social - a discriminação (para arrumar trabalho, para frequentar a escola, ou se inserir em grupos sociais) a xenofobia, as dificuldades enfrentadas pelo migrante pelo simples fato de vir de outro país, ainda são uma prerrogativa e persistem para além dos direitos conquistados.

\section{A questão do refúgio e território - à guisa de conclusão}

Em tempos de instabilidade sociopolítica e econômica na Venezuela, a migração tem se mostrado como uma alternativa para fugir da crise. Os países fronteiriços têm sido os principais acolhedores da população venezuelana e, no caso do Brasil os números de solicitações de refúgio já superaram os 30 mil (MINISTÉRIO DA JUSTIÇA, 2018).

No entanto, os discursos políticos e midiáticos conservadores têm dificultado ainda mais a vida dos migrantes venezuelanos que para cá se dirigiram. O presidente eleito já manifestou que deveriam ser criados "campos de refugiados" para os migrantes venezuelanos de forma a conter o avanço destes pelo território brasileiro (O GLOBO, 2018). Estes discursos potencializam a figura de um migrante que não deve ser acolhido por ser um gerador de problemas, representando os migrantes como pessoas nocivas 
ao território nacional, aumentando as diferenças existentes entre o que é ser natural ou estrangeiro. Este mecanismo possibilita criar obstáculos mais cruéis às duras realidades enfrentadas pelos migrantes, muitas vezes negando-lhes acesso aos serviços básicos (saúde, educação, moradia) e impedindo-os de trabalhar e assim, poderem reconstruir suas vidas.

A mobilidade imposta aos migrantes para movimentar as engrenagens do capital, sendo estas motivadas ou não por questões de trabalho, nega-lhes o direito à uma vida onde os vínculos territoriais possam ser valorizados, onde muitas vezes, as políticas migratórias, discutem processos de assimilação e não de integração do migrante. Entendendo assim, que o migrante é uma presença provisória e não deve alterar a paisagem original do território de acolhida. No entanto, ao migrante, que teve de romper com seus laços originais a formação de novas territorialidades é essencial para sua sobrevivência. SAYAD (2000: 13) lembra da importância da noção de pertencimento nacional, que se faz:

ao tempo, ao espaço, ao grupo, os principais quadros que estruturam a vida social e mesmo toda vida social e mesmo toda existência individual - existir no tempo, no espaço e no interior de um grupo social (é a condição da existência política) - sempre está em causa um pertencimento nacional, um pertencimento nacionalmente definido: o pertencimento a cada um a seu tempo é um pertencimento à história nacional; o pertencimento ao espaço é um pertencimento ao território nacional; o pertencimento ao grupo dos nacionais é um pertencimento à nação e à nacionalidade que lhe são comuns.

A mobilidade implica numa "perda de território", em decisões que precisam de deslocamento, que implica perdas de amigos, de relações, de "lugares" etc. De outra forma, entender esse processo de migração e da desterritorialização, nos permite demonstrar e problematizar como se deram e se dão as relações de re-territorialização no novo lugar, no país de acolhida, das novas relações e tudo que envolve essa nova experiência. Assim, os processos de migração e re-territorialização se sobrepõem na análise, na tentativa de compreender as relações socioespaciais de deslocamento e dos 
significados da mudança, da mudança que sempre implica nova mediação pelo e no espaço compreendendo, a produção/destruição/reconstrução de territórios na mobilidade. Esse processo de des-re-territorialização é uma condição do ser imigrante, uma condição paradoxal, uma condição de "destruição" e de "reconstrução", reinvenção de territórios e de territorialidades na/da mobilidade espacial.

[...] mudar de espaço - deslocar-se no espaço, que é sempre um espaço qualificado - é descobrir e aprender simultaneamente que o espaço é, por definição, um "espaço nostálgico", um lugar aberto a todas as nostalgias, isto é, carregado de afetividade. O espaço não é, portanto, esse espaço abstrato, contínuo e homogêneo dos matemáticos, esse conjunto de lugares indiferentes e intercambiáveis entre os quais se pode ir e vir em espírito, e com toda a liberdade, como o postula a geometria. Se existe uma nostalgia agarrada ao espaço, e se este é no fundo de si mesmo um lugar de nostalgia, como se experimenta em todos os deslocamentos, é porque se trata de um espaço vivo, concreto, qualitativa, emocional, e até mesmo apaixonadamente distinto (SAYAD, 2000: 12).

Neste cenário, o objetivo constitui-se em explorar a relação entre os processos de migração e des-re-territorialização, especialmente a partir da partida, do "abandono de território", junto aos inúmeros motivos que se explicam através das falas dos migrantes. Esses processos podem ser verificados e identificados quando migrantes entrevistados explicam os motivos pelos quais os venezuelanos tiveram que deixar o seu país. A migração, então, permite demonstrar e problematizar a desterritorialização (a perda do território) e a reterritorialização (a reconstrução do território).

Assim, seria importante que as políticas migratórias dos Estados refletissem sobre o processo de integração dos migrantes à sociedade, de forma a garantir-lhes o direito ao uso do território de forma a valorizar sua cultura e possibilitar que a individualidade do migrante possa ser preservada ao celebrar o que estes consideram típico de seu território , afinal em tempos de mundo globalizado conceitos como multiculturalismos, direitos humanos e legislação trabalhistas unificados, respeito às diferenças culturais e as territorialidades deveriam ser considerados (POVOA-NETO, 2008) 
O território, como espaço dominado e/ou apropriado, manifesta hoje um sentido multi-escalar e multi-dimensional que só pode ser devidamente apreendido dentro de uma concepção de multiplicidade, de uma multiterritorialidade. E toda ação que efetivamente se pretenda transformadora, hoje, necessita, obrigatoriamente, encarar esta questão: ou se trabalha com a multiplicidade de nossos territórios, ou não se alcançará nenhuma mudança positivamente inovadora. Pensar multiterritorialmente é a única perspectiva para construir uma outra sociedade, ao mesmo tempo mais universalmente igualitária e mais multiculturalmente reconhecedora das diferenças humanas (HAESBAERT, 2004: 19).

Estes elementos, ao contrário do que afirmam os discursos conservadores, não implicam em perda da soberania do Estado, mas sim na garantia de direitos humanos plenos à todos àqueles que de alguma forma são forçados a se deslocar pelo mundo, assegurando o direito a diversidade e a pluralidade cultural. Assim, os esforços realizados pelas organizações de acolhimento ao migrante em terras brasileiras buscam legitimar os direitos resguardados pela nova Lei do Migrante e possibilitar que, neste processo de interiorização, perspectivas mais humanas e solidárias lhes sejam apresentadas incluindo o aceso ao trabalho .

Segundo a ONU (2007) existem mais brasileiros no exterior (em torno de 3 milhões) do que estrangeiros no Brasil (em torno de 1 milhão), no entanto, a migração de venezuelanos para o Brasil ganhou grande destaque nas mídias aumentando a proporção real de entrada destes no país e causando muitos conflitos com a população local. O fato é que ao pensar sobre a fluidez do mundo contemporâneo não se pode esquecer que a mobilidade, a desterritorialização e os processos de preconceitos e xenofobia vão acontecer a todos migrantes, por isto a luta pelo respeito ao multiculturalismo e a multiterritorialidade deve ser feito de forma ampla e por todos os Estados Nacionais

\section{Referências Bibliográficas}

AMAZÔNIA.ORG. Transporte caro ou dias a pé: como é a travessia dos venezuelanos 
para viver no Brasil. Disponível em: https://amazonia.org.br/2018/02/transportecaro-ou-dias-a-pe-como-e-a-travessia-dos-venezuelanos-para-viver-no-brasil/.

BATISTA, S.; BONINI, L. M. M. Lei de migração no Brasil à luz da crise humanitária no mundo, 2017. Disponível em https://ambitojuridico.com.br/cadernos/direitoshumanos/lei-de-migracao-no-brasil-a-luz-da-crise-humanitaria-no-mundo/. Acesso em 11 de março de 2021.

BBC. Quais são os países com as maiores reservas de petróleo e por que isso não é sempre um sinal de riqueza. Disponível em: https://www.bbc.com/portuguese/internacional-47795371. Acesso em 28 de novembro de 2019.

Brasil recebe apenas 2\% dos 2,3 milhões de venezuelanos expulsos pela crise. Disponível em: https://www.bbc.com/portuguese/brasil-45251779. Acesso em 28 de novembro de 2019.

CÂMARA DOS DEPUTADOS. Brasil recebe cerca de 600 migrantes venezuelanos por dia; audiência pública discute direitos humanos para quem busca abrigo no país. Publicado em: 19 de set. 2018. Disponível em: <https://www2.camara.leg.br/atividade-legislativa/comissoes/comissoespermanentes/cdhm/noticias/brasil-recebe-cerca-de-600-migrantes-venezuelanospor-dia-audiencia-publica-discute-direitos-humanos-para-quem-busca-abrigo-nopais> Acesso em 23 de março de 2019.

ECODEBATE. O colapso da Venezuela e a maldição do petróleo. Disponível em: https://www.ecodebate.com.br/2016/07/18/o-colapso-da-venezuela-e-a-maldicaodo-petroleo-artigo-de-jose-eustaquio-diniz-alves/. Acesso em 28 de novembro de 2019.

G1. Preço do petróleo Brent se estabiliza ao redor de US\$ 64 com foco na retomada de produção saudita. Disponível em: https://g1.globo.com/economia/noticia/2019/09/23/preco-do-petroleo-brent-seestabiliza-ao-redor-de-us-64-com-foco-na-retomada-de-producao-saudita.ghtml. Acesso em 28 de novembro de 2019.

Após ataques de brasileiros, 1,2 mil venezuelanos deixaram o país, diz Exército. Disponível em: https://g1.globo.com/rr/roraima/noticia/2018/08/19/pacaraimatem-ruas-desertas-apos-confronto-entre-brasileiros-e-venezuelanos.ghtml. Acesso em 28 de novembro de 2019.

GAUDEMAR, J. P. Mobilidade do trabalho e acumulação do capital. Lisboa: Editorial Estampa, 1977. 
GAZETA DO POVO. Cinco gráficos que explicam a crise na Venezuela. Disponível em: https://www.gazetadopovo.com.br/mundo/cinco-graficos-que-explicam-a-crise-davenezuela-20k14seeg7h03hs2pg7pi52ad/. Acesso em 28 de novembro de 2019.

GUERRA, Sidney. A NOVA LEI DE MIGRAÇÃO NO BRASIL: AVANÇOS E MELHORIAS NO CAMPO DOS DIREITOS HUMANOS IN: Revista de Direito da Cidade, vol. 09, no 4. ISSN 2317-7721 pp. 1717-1737.

HAESBAERT, Rogério. Da multiterritorialidade aos novos muros: paradoxos da desterritorialização contemporânea. Niterói, 2017.

. O Mito da Desterritorialização: do "Fim dos Territórios" à Multiterritorialidade.

2. ed. Rio de Janeiro: Bertrand Brasil, 2006.

- Da Desterritorialização à Multiterritorialidade. Anais do X Encontro de Geógrafos da América Latina. São Paulo: Universidade de São Paulo, 2005a, pp. 67746792.

MARINUCCI Roberto. Criminalização das migrações e dos migrantes In: REMHU - Rev. Interdiscip. Mobil. Hum., Brasília, Ano XXIII, n. 45, p. 7-10, jul./dez. 2015.

Paradigmas de políticas migratórias e o Brasil. Brasília: CSEM, maio de 2012.

MILESI, Rosita; COURY, Paula; ROVERY, Julia. Migração Venezuelana ao Brasil: discurso político e xenofobia no contexto atual. 2018. Disponível em: https://seer.ufrgs.br/aedos/article/viewFile/83376/49791.

OLIVEIRA, Antônio Tadeu Ribeiro De. Nova lei brasileira de migração: avanços, desafios e ameaças. Rev. bras. estud. popul. vol.34 no.1 São Paulo Jan./Apr. 2017.

O TEMPO. Venezuelanos são vítimas de xenofobia em Roraima. Disponível em: https://www.otempo.com.br/brasil/venezuelanos-s\%C3\%A3o-v\%C3\%ADtimas-dexenofobia-em-roraima-1.1572431. Acesso em: 28 de junho de 2019.

PÓVOA-NETO, Hélion. O erguimento de barreiras à migração e a diferenciação dos "direitos à mobilidade. In: Revista Interdisciplinar da Mobilidade Humana, Ano XVI Número $31-2008$.

. A criminalização das migrações na nova ordem internacional In: POVOA NETO, Helion; FERREIRA, Ademir Pacelli (org). Cruzando Fronteiras Disciplinares. Rio de Janeiro: Revan, 2005.

RODRIGUES, Francilene. Migração transfronteiriça na Venezuela. Estudos avançados, vol.20 no.57 São Paulo May/Aug. 2006. 
SANTOS, Fernanda Naomi Zaphiro; VASCONCELOS, Thamires Marques. Venezuelanos no Brasil: da crise econômica para a crisepolítica e midiática. Disponível em: <http://www.encontro2016.rj.anpuh.org/resources/anais/42/1465525214_ARQUIV O_VenezuelanosnoBrasil-dacriseeconomicaparaacrisepoliticaemidiatica.pdf $>$ Acesso em 23 de março de 2019.

SAYAD, Abdelmalek (2000). O retorno: elemento constitutivo da condição do imigrante. Travessia - Revista do Migrante, São Paulo: CEM, ano XIII, número especial, jan./2000.

SENADO FEDERAL. Estatuto do Estrangeiro: legislação e correlatada. 2014. Disponível em:

<https://www2.senado.leg.br/bdsf/bitstream/handle/id/508142/000986045.pdf?se quence=1> Acesso em 23 de março de 2018.

Fluxo migratório de venezuelanos. Disponível em: http://legis.senado.leg.br/sdleg-getter/documento/download/d343cbc3-4b87498d-82df-7db15d4cfe31. Acesso em 01 de dezembro de 2019.

SIMÕES, Gustavo da Frota. Venezuelanos em Roraima: características e perfis da migração Venezuelana para o Brasil. 2017. Disponível em: <https://www.kas.de/c/document_library/get_file?uuid=fa9065e2-c184-56550c04-1381156aca09\&groupld=265553> Acesso em 23 de março de 2019.

TERRA. Venezuelanos são agredidos e expulsos em Roraima. Publicado em: 18 ago. 2018. Disponível em: https://www.terra.com.br/noticias/brasil/venezuelanos-saoagredidos-e-expulsos-emroraima,59fefed7975a667de82952def3364d6cclh0qze0.html> Acesso em 23 de março de 2019. 